\title{
Stress Perceived by the Caretakers Attending to Patients with Cancer Problems
}

\author{
M. Sandhya Rani ${ }^{1}$, Nasreen Banu ${ }^{2}$ \\ ${ }^{1}$ Department of Human Development And Family Studies, College Of Home science, Professor Jayashankar Telangana State Agricultural \\ University, Hyderabad India \\ ${ }^{2}$ (Major Advisor) Principal Scientist,AICRP- Human Development, PG \& RC, Professor Jayashankar Telangana State Agricultural \\ University, Hyderabad India
}

\begin{abstract}
The present study makes an attempt to understand the stress perceived by the caretakers attending to patients with cancer problems. Caretakers who were ready and willing to extend their cooperation for in depth interview were selected as population for the study. Thus a total number of 80 caretakers were selected purposively for conducting the present study. The results revealed that more than 56 percent of caretaker's perceived high stress, 33 percent perceived average stress and only 11 percent perceived very low stress.
\end{abstract}

Keywords: Caretakers, Cancer problems.

\section{Introduction}

Becoming a parent, is one of the most powerful of the human experiences, is often accompanied with feelings of celebration and relief, but it can also be a time of anxiety, and stress. The term "Parenting" is derived from the Latin root pario, meaning life-giver, and encompasses much more than just the care giving activities parents perform.

As a parent, the fact that the patient has cancer problem is one of the worst situations to face. Everyone will be worried and under considerable problems. Parents will worry that the child will suffer and the family life is going to be completely disrupted. Parents may feel numb or as though you have been hit physically and may feel confused, or unable to hear, remember or think clearly when you are given information about your child's diagnosis or treatment. The numbness may alternate with feeling overwhelmed by very painful and powerful emotions.

According to Merriam-Webster's Collegiate Dictionary (1993) one definition of stress is "a constraining force or influence such as a physical, chemical, or emotional factor that causes bodily or mental tension and may be a factor in disease causation".

Stress is caused by changes in a person's life style, financial problems, environmental episodes, personal loss, or negative emotions (callan, 1990et al.). Stress can also be an outcome resulting from interactions with people, situations, and the environment (Romas and Sharma, 2000). Stress can be caused by small everyday hassles, as well as pervasive, ongoing factors, which may arise from specific events, but have long-term ramifications (Bailey and Simeonsson, 1988; Romas and Sharma, 2000).

\section{Research Method}

A total number of 80 caretakers who were ready and willing to extend their cooperation for in depth interview were selected as population for the present study. The sample was limited to caretakers for two reasons. First much of the research on family care giving which has been done in aboard only this area of study is almost non- existent in the state of Telangana. Secondly, reports have suggested that parents are particularly vulnerable to the strains of illness experienced due to multiple roles to be shouldered. The main focus of the study was to provide various alternative strategies for the caretakers.

\section{Research Findings and Discussion}

Caretaker's general profile: Includes variables such as age, gender, education, occupation, religion, relationship with the patient, marital status, family type and family income.

For conducting in depth interview and to share personal information regarding caretaker's perceptions and variables contributing to the stress perceived by the caretakers attending to patients with cancer problems. Only cooperative caretakers were selected.

Caretakers who were ready and willing to extend their cooperation for in depth interview were selected as population for the study. Thus a total 80 caretakers were selected purposively for conducting the present study.

Patients' general profile: It includes patient's age, gender, education, ordinal position, relationship with the caretaker. Initial survey was done through website and through personal contacts and 10 centres (Hospitals) were identified catering to the needs of the cancer patients. The centres (Hospitals) were then contacted in person through phone to find out the patients with cancer. Based on the availability and frequency of these children with cardiac, 4 hospitals were identified.

After secondary survey out of 4 Hospitals, the number is further reduced to 2 based on the continuous flow of cancer patients to the hospitals and duration of stay ranged from 10 days to one month, which was convenient to conduct indepth in interviews with the caretaker about the patient. 


\section{Description of the Cardiac Problems}

Cancer illness is the most acute pressure, which any family may experience and it also creates a potential threat equally to both the victim and the caretaker.

For the patient, the threat involves painful medical procedures, surgeries, and its side effects, and frequent hospitalization.

\section{Stress Perceived by the Caretaker attending to Patients with Cancer Problems}

Stress perceived by the caretaker attending to children with cardiac problems $(\mathrm{n}=80)$

\begin{tabular}{|c|c|c|c|c|c|c|c|c|}
\hline \multirow{3}{*}{ S. No. } & \multirow{3}{*}{ Area } & \multirow{2}{*}{ Category } & \multicolumn{2}{|c|}{$\begin{array}{c}\text { Males } \\
(\mathrm{n}=24)\end{array}$} & \multicolumn{2}{c|}{$\begin{array}{c}\text { Females } \\
(\mathrm{n}=56)\end{array}$} & \multicolumn{2}{c|}{$\begin{array}{c}\text { Total } \\
(\mathrm{N}=80)\end{array}$} \\
\cline { 3 - 9 } & & & $\mathrm{F}$ & $\%$ & $\mathrm{~F}$ & $\%$ & $\mathrm{~F}$ & $\%$ \\
\hline \multirow{2}{*}{1.} & \multirow{2}{*}{ Stress } & Low & 3 & 13 & 6 & 11 & 9 & 11 \\
\cline { 3 - 9 } & & Average & 7 & 29 & 19 & 34 & 26 & 33 \\
\hline & High & 14 & 58 & 31 & 55 & 45 & 56 \\
\hline
\end{tabular}

The above table presents stress perceived by the caretaker's attending to patients with cancer: perceived stress scale is used to find out the stress related to parenting a chronicallyill child. The scale focuses areas such as: Emotions, Social support system, Personality, Health and Well-being. It was observed from the table that $(56 \%)$ of the parent's perceived high stress, (33\%) perceived average stress, and only (11\%) percent perceived low stress

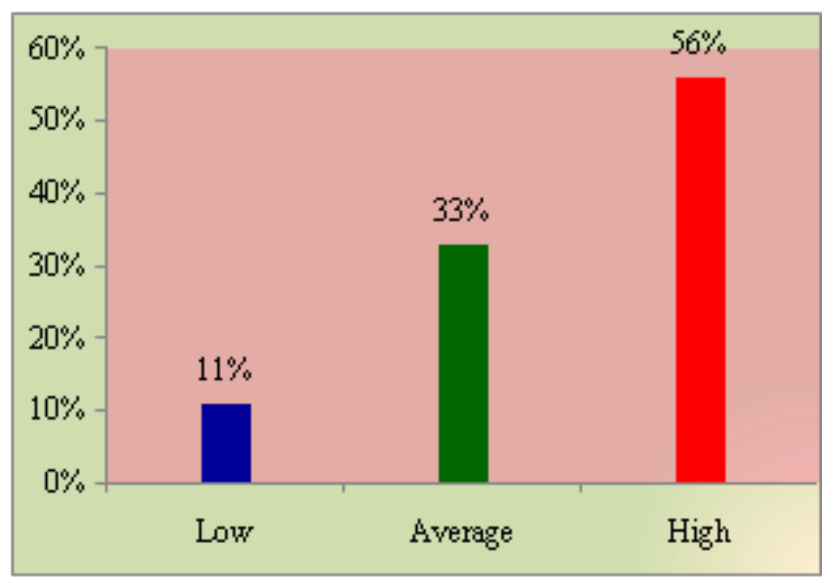

\section{Conclusion}

The results revealed that more than 56 per cent of the parents' perceived high stress, 33 per cent perceived average stress and only 11 percent perceived very low stress.

Two third of the parents perceived high stress. This could be as cardiac problem is considered as an incurable disease, critical and traumatic. The feeling that something may go wrong (very sick or die) may cause discomfort and insecurity each and every moment. Besides attending to the sick child, the caretakers also have to manage different things like household activities, family needs, personal needs, attending to other children, and managing health problems so on. All these things may add up to increase stress among the caretakers.

Hoekstra et al. (2009) conducted a longitudinal study on coping and psychological adjustment of parents of pediatric cancer parents found that trait anxiety was the strongest predictor of both fathers and mothers future distress about the patient's health. However, both fathers and mothers reported significantly higher rates of perceived vulnerability, regardless of surgery or severity of the disease.

\section{References}

[1] Bailey, D.B. and Simeonson, R.J. 1988. Family assessment in early intervention. Columbus, $\mathrm{OH}$ : Merrill Publishing company.

[2] Callanan, C.R. 1990. Since owen. Baltimore, MD: Johns Hopkins University Press.

[3] Merriam-Webster's Collegiate Dictionary Expert: Merriam-Webster. 1993. Online Dictionary.

[4] Romas, J.A. and Sharma, M. 2000. Practical stress management (2nd ed.). Needham Heights, MA:Allyn and Bacon.

[5] Hoekstra - Weebers, J.E., Jaspers, J.P.C., Kamps, W.A and Klip. E.C. 2000. Coping and Psychological Adjustment of Parents of Pediatric Cancer Parents: A Longitudinal Study. In Parental Adoption to Pediatric Cancer. 